\title{
Effect of Cardioxane and Selenium on Lipoperoxidation and Levels of Dopamine in Rat Brain and Heart
}

\author{
David Calderón Guzmán1, Norma Osnaya Brizuela1, Gerardo Barragán Mejía², \\ Hugo Juárez Olguín ${ }^{3,4^{*}}$ (i), Lulú Sánchez Reyes ${ }^{3,4}$, Armando Valenzuela Pereza1, \\ Norma Labra Ruiz' ${ }^{1}$, Daniel Santamaría del Angel1
}

\author{
${ }^{1}$ Laboratory of Neurosciences, Instituto Nacional de Pediatría (INP), Mexico City, Mexico \\ ${ }^{2}$ Laboratory of Experimental Bacteriology, INP, Mexico City, Mexico \\ ${ }^{3}$ Laboratory of Pharmacology, INP, Mexico City, Mexico \\ ${ }^{4}$ Faculty of Medicine, Universidad Nacional Autónoma de Mexico, Mexico City, Mexico \\ Email: *juarezol@yahoo.com, *adrianos27@hotmail.com
}

How to cite this paper: Guzmán, D.C., Brizuela, N.O., Mejía, G.B., Olguín, H.J., Reyes, L.S., Pereza, A.V., Ruiz, N.L. and del Angel, D.S. (2019) Effect of Cardioxane and Selenium on Lipoperoxidation and Levels of Dopamine in Rat Brain and Heart. Neuroscience \& Medicine, 10, 354-368. https://doi.org/10.4236/nm.2019.104026

Received: August 28, 2019

Accepted: October 18, 2019

Published: October 21, 2019

Copyright $\odot 2019$ by author(s) and Scientific Research Publishing Inc. This work is licensed under the Creative Commons Attribution-NonCommercial International License (CC BY-NC 4.0).

http://creativecommons.org/licenses/by-nc/4.0/

\begin{abstract}
Background: Cardioxane has been probed in patients with advanced malignancies to protect the heart. Selenium, an essential micronutrient exerts varieties of functions such as antioxidant. The aim of this study was to test if cardioxane (CDX) and selenium (Se) have additive antioxidant protective effect on brain and heart, and their relation with dopamine levels. Methods: Thirty-six male Wistar rats divided in groups of 6 animals each, were treated as follows: G1, saline solution $0.9 \%$ (control); G2, $100 \mathrm{mg} / \mathrm{kg}$ of CDX; G3, 60 $\mu \mathrm{g} / \mathrm{kg}$ of Se; G4, $20 \mathrm{mg} / \mathrm{kg}$ of 3-nitropropionic acid (3NP); G5, 3NP + CDX and G6, 3NP + Se. 3NP was used as an oxidative stress inducer. Drugs were administered intraperitoneally for 5 days. The animals were sacrificed on the last day of treatment and the brain and heart were extracted and used to measure lipid peroxidation, dopamine, glutathione (GSH), ATPase, calcium, and $\mathrm{H}_{2} \mathrm{O}_{2}$. Results: In $\mathrm{G} 2$ and G5, dopamine decreased in cortex and striatum while GSH increased in heart, cortex and cerebellum/medulla oblongata. ATPase activity increased in heart and cortex of groups 2, 3, 5 and 6. Lipoperoxidation and $\mathrm{H}_{2} \mathrm{O}_{2}$ increased in cortex of animals treated with 3NP. Conclusion: These results suggest that CDX increases antioxidant capacity in the brain and heart while selenium promotes alteration in dopamine metabolism in view of the capacity of $3 \mathrm{NP}$ to generate free radicals.
\end{abstract}

\section{Keywords}

Brain, Dopamine, Heart, Cardioxane, Selenium, 3-Nitropropionic Acid 


\section{Introduction}

Neurological disorders bring about an increase in intracellular concentrations of $\mathrm{Ca}^{2+}$, thereby causing oxidative damage and increasing reactive nitrogen species (RNS) [1]. In neurodegenerative disorders, oxidative stress provokes mitochondrial ultrastructural alterations and DNA damage [2]. These deleterious effects are the primary events in 3NP toxicity, which induces neurodegeneration in Wistar rats. Recent studies suggest that some cardioprotective drugs might affect brain areas [3].

Cardioxane (CDX) (also known as dexrazoxane) is a bidentate chelator of divalent cations that has a short plasma half-life. As a derivative of ethylenediaminetetraacetic acid (EDTA), CDX chelates iron, and thus reduces the number of metallic ions bonding with anthracycline, and consequently decreases the formation of superoxide radicals. Cardioxane has been probed in patients with advanced malignancies to protect the heart [4].

Free radicals are known to damage some organs, and the central nervous system (CNS) is particularly susceptible and extremely dependent on the amounts of antioxidants, especially during development, when brain metabolism and growth rates are high [5]. These also regulate energy and glucose homeostasis by acting on hypothalamic neural circuits and higher brain circuits such as the dopaminergic system [6].

In dopaminergic axons, selenium transport protein (selenoprotein $\mathrm{P}$ ) has been found. These selenoproteins are molecules, which contain selenium in form of amino acid selenocysteine, and many of these proteins have antioxidant functions [7]. Brain plasma membrane phospholipids are in close contact with structural proteins embedded in the lipid bilayer [8], through which the ionic interchange occurs by the action of $\mathrm{Na}^{+}, \mathrm{K}^{+}$ATPase that stimulates $\mathrm{Na}^{+}$and $\mathrm{K}^{+}$flow [9]. The inhibition of $\mathrm{Na}^{+}, \mathrm{K}^{+}$ATPase activity induces excitatory amino acids release within the CNS [10].

Selenium is an essential micronutrient which is required in small amount by the body. Its ability to form multiple selenoproteins makes it exert varieties of functions such as antioxidant, immunological and thyroid functions. The most important biological activity of Se seems to be through the enzyme glutathione peroxidase (GSH-Px), which in cooperation with vitamin "E" and some other antioxidants, is able to reduce the destructive effects of peroxidative reactions in living cells, thus decreasing the process of cell aging. In addition, it helps in the absorption of lipids and tocopherols in the digestive tract through pancreatic lipase. It forms part of some enzymes of the microorganisms found in the lumen Selenium has high biochemical chemical activity in the body. It acts as a remover of heavy metals and as a detoxifying agent against $\mathrm{Cd}, \mathrm{Hg}, \mathrm{Al}, \mathrm{As}, \mathrm{Ag}$ and $\mathrm{Pb}$. However, when the consumption of selenium is high, it tends to accumulate to toxic level in the body and can bring about tissue injuries.

In inflammation and oxidative stress, selenoprotein dysfunction may contribute to disease progression. Most studies on the role of selenium in endothelial 
processes have demonstrated selenium-dependent endothelial functions and explain how cells and tissues adapt to inflammatory insults [11]. Selenium is widely used as a cardioprotective agent. It also plays an important role as a cofactor of some antioxidant enzymes involved in glutathione metabolism [12]. The energy/excitotoxic hypothesis for 3-NP toxicity should include a dopamine role, because the vulnerability of striatal neurons to 3-NP depends on an intact dopamine input. It seems likely that the striatal selectivity of 3-NP lesions is attributable to the fact that striatum is a major target for both dopaminergic and glutamatergic inputs thus, making it the most vulnerable region in the 3-NP-intoxicated brain.

The purpose of the present study is to determine the effect of cardioxane and selenium on selected oxidative stress markers in the heart as well as the levels of dopamine in brain of experimental rats treated with $3 \mathrm{NP}$ as a neurodegeneration as occur in Huntington disease model due to oxidative stress.

\section{Material and Methods}

Male Wistar rats (36 in total) of $100 \mathrm{~g}$ weight each were procured and evenly partitioned in six groups for treatment. Group 1 (control), was given $0.9 \%$ Saline solution. Group 2 was administered $100 \mathrm{mg} / \mathrm{kg}$ of cardioxane (CDX). Group 3 was treated with $60 \mu \mathrm{g} / \mathrm{kg}$ of Sodium Selenite (Se). Group 4 received 3NP at $20 \mathrm{mg} / \mathrm{kg}$. Group 5 was administered a combination of $3 \mathrm{NP}+\mathrm{CDX}$ and group 6, a combination of $3 \mathrm{NP}+$ Se. The treatments were intraperitoneally administered for 5 consecutive days. The doses administered were based on previous studies of our laboratory. To ensure optimum experimental conditions, the animals were kept in a room with mass air displacement and light:dark exposition cycle of 12:12 h. The room temperature and relative humidity were maintained at $22^{\circ} \mathrm{C} \pm 2{ }^{\circ} \mathrm{C}$ and $50 \% \pm 10 \%$ respectively. The rats were fed with balanced food based on Rodent diet 5001, while drinking water was without restrain. The animals were sacrificed by decapitation $60 \mathrm{~min}$ after the last treatment. The brain and heart of each animal were immediately extracted and immersed in a solution of $0.9 \mathrm{NaCl} \%$ at $4^{\circ} \mathrm{C}$. The brain was dissected and separated in cortex, cerebellum/medulla oblongata and striatum. The dissected brain regions were stored in 5 volumes of $0.05 \mathrm{M}$ TRIS- $\mathrm{HCl}$ at $\mathrm{pH} 7.4$ and employed in the evaluation of $\mathrm{H}_{2} \mathrm{O}_{2}$ level and ATPase activity. The measurement of reduced glutathione (GSH), dopamine levels and calcium concentrations were carried out using an aliquot homogenized in $0.1 \mathrm{M}$ of perchloric acid $\left(\mathrm{HClO}_{4}\right)(50: 50 \mathrm{v} / \mathrm{v})$.

All experimental procedures and animal management were performed following the national and international rules, and in accordance with the Guidelines for Ethical Control and Supervision in the Care and Use of Laboratory Animals.

\subsection{Technique for Heart Extraction}

The sacrificed rats were kept in a ventral position. Then, an incision in the abdo- 
minal wall along the infra-supra umbilical plane was made. The upper cavity was opened, thereby exposing the heart. This was excised from the base and weighed. Then, it was homogenized in ultrasonic sonicator (Vibra Cell, Sonic and Materials Inc. USA), with three 5-second lapses at $60 \mathrm{Hertz}$, and stored at $-20^{\circ} \mathrm{C}$ until analysed.

\subsection{Dopamine (DA) Levels}

The DA levels were obtained using the technique reported by Calderon et al. [13]. The homogenized tissue was centrifuged at $9000 \mathrm{rpm}$ for $10 \mathrm{~min}$ in a microcentrifuge at room temperature (Hettich Zentrifugen, model Mikro 12 - 42, Germany). An aliquot of this was taken and mixed with $1.9 \mathrm{ml}$ of buffer $(0.003 \mathrm{M}$ octyl-sulphate, $0.035 \mathrm{M} \mathrm{KH}_{2} \mathrm{PO}_{4}, 0.03 \mathrm{M}$ citric acid, $0.001 \mathrm{M}$ ascorbic acid). The mixture was poured in a test tube and subjected to $5 \mathrm{~min}$ of incubation at room temperature in absolute darkness. Afterwards, the samples were spectrofluorometrically read under $282 \mathrm{~nm}$ excitation and $315 \mathrm{~nm}$ emission lengths (Perkin Elmer LS 55, England), and using FL Win Lab version 4.00.02 software, values of DA levels were inferred from a previously standardized curve and stated as $\mu \mathrm{M} / \mathrm{g}$ of wet tissue.

\subsection{Reduced Glutathione (GSH) Levels}

The GSH levels were obtained using a modified method of Hissin and Hilf [14]. The tissue homogenized in perchloric acid $\left(\mathrm{HCLO}_{4}\right)$ was obtained and centrifuged at $9000 \mathrm{rpm}$ for $5 \mathrm{~min}$ (Mikro 12 - 42, Germany centrifuge). From the resulting supernatant, $20 \mu \mathrm{L}$ aliquot was taken and mixed with $1.8 \mathrm{~mL}$ of phosphate buffer $\mathrm{pH} 8.0$ with EDTA $0.2 \%$ and $100 \mathrm{~mL}$ of ortho-phthaldehyde (OPT) $1 \mathrm{mg} / \mathrm{mL}$ in methanol. The mixture was put in a test tube and subjected to 15 min of incubation in complete darkness. Subsequently, the samples were spectrofluorometrically read under an excitation and emission wavelengths of 350 and $420 \mathrm{~nm}$ respectively (PERKIN ELMER LS 55). Using FL Win Lab version 4.00.02 software, values of GSH levels were calculated from a previously standardized curve and reported as $\mu \mathrm{M} / \mathrm{g}$ of wet tissue.

\subsection{Calcium Concentrations}

To obtain the concentration of calcium, Ca-Color Arsenazo III AA direct colorimetric method kit (Wiener Lab Rosario, Argentina) was used. The liquid of the supernatant from the homogenized brain and heart tissues of the animal groups was poured in the kit, and the calcium concentrations were read using internal standard. The values were expressed in $\mathrm{mg} / \mathrm{g}$ wet tissue.

\subsection{Total ATPase Activity}

ATPase activity was analysed using the method of Calderón et al. [15]. This entails $15 \mathrm{~min}$ of incubation of $1 \mathrm{mg}(10 \%) \mathrm{w} / \mathrm{v}$ of the brain and heart tissues homogenized in TRIS- $\mathrm{HCl} 0.05 \mathrm{M} \mathrm{pH} 7.4$, in a solution that contains $3 \mathrm{mM} \mathrm{MgCl}_{2}$, 
$7 \mathrm{mM} \mathrm{KCl}$, and $100 \mathrm{mM} \mathrm{NaCl}$. Subsequently, $4 \mathrm{mM}$ tris-ATP was added to the incubated solution and subjected to another incubation that lasted for $30 \mathrm{~min}$ at $37^{\circ} \mathrm{C}$ in a shaking water bath (Dubnoff Labconco). The reaction was detained using $100 \mu \mathrm{L} 10 \%$ trichloroacetic acid w/v. After, the samples were centrifuged at $1100 \mathrm{rpm}$ and $4^{\circ} \mathrm{C}$. The measurement of the inorganic phosphate (Pi) of the supernatant aliquot was made in triplicate using the method of Fiske and Subarrow [16]. The absorbance of the supernatant was spectrophotometrically read at $660 \mathrm{~nm}$ using Helios- $\alpha$, UNICAM and this was stated in $\mathrm{mM} \mathrm{Pi/g}$ wet tissue per min.

\section{6. $\mathrm{H}_{2} \mathrm{O}_{2}$ Concentration}

The concentration of $\mathrm{H}_{2} \mathrm{O}_{2}$ was determined with a modified technique of Arsu [17]. This implies homogenizing all the brain regions (striatum, cortex, cerebellum/medulla oblongata) in $3 \mathrm{~mL}$ of TRIS-HCl $0.05 \mathrm{M} \mathrm{pH} 7.4$ buffers. Thereafter, $100 \mu \mathrm{l}$ of the diluted homogenates was mixed with $1 \mathrm{~mL}$ of potassium dichromate solution $\left(\mathrm{K}_{2} \mathrm{Cr}_{2} \mathrm{O}_{7}\right)$. Subsequently, the blends were subjected to $15 \mathrm{~min}$ of heating until boiling point (Thermomix 1420), and then cooled for 5 min by an ice bath. Next, they were passed through a centrifugation process at $4500 \mathrm{rpm}$ which lasted 5 min using Sorvall RC-5B Dupont. The floating tissues were obtained and placed in a spectrophotometer (He $\lambda$ ios- $\alpha$ of UNICAM), and the absorbance was read in triplicates at $570 \mathrm{~nm} . \mathrm{H}_{2} \mathrm{O}_{2}$ concentrations were reported in $\mu$ Moles.

\subsection{Determination of Lipid Peroxidation}

The determination of the values of TBARS was accomplished using the method of Gutteridge and Halliwell [18]. This entails homogenizing every tissue sample in $5 \mathrm{~mL}$ of phosphate buffer $\mathrm{pH}$ 7.4. An aliquot $(1 \mathrm{~mL})$ of this homogenate was taken and mixed with thiobarbituric acid (TBA) solution that contains TBA (1.25 $\mathrm{g})$, trichloroacetic acid (40 g) and concentrated $\mathrm{HCl}(6.25 \mathrm{~mL})$ dissolved in 250 $\mathrm{mL}$ deionised water. The mixture was subjected to $30 \mathrm{~min}$ of heating (Thermomix 1420) until water boiling point, and cooled by ice bath for $5 \mathrm{~min}$. Afterwards, the samples were passed through a centrifugation process at $4500 \mathrm{rpm}$ during 15 min (Sorvall RC-5B Dupont). The supernatant of the samples was obtained and placed in Hedios- $\alpha$, UNICAM spectrophotometer and the absorbance was read in triplicates at $532 \mathrm{~nm}$. The concentration of thiobarbituric acid reactive substances (TBARS) was reported as $\mu$ moles of malondialdehyde per gram of wet tissue.

\subsection{Statistical Analysis}

Kruskal-Wallis and ANOVA tests with their corresponding contrasts and previous variance homogeneity were used. Values restricted to $\mathrm{p}<0.05$ were considered statistically significant [19]. JMP Statistical Discovery from SAS version 8.0.0 software was used. 


\section{Results}

\section{1. $\mathrm{H}_{2} \mathrm{O}_{2}$}

In cortex, the administration of $3 \mathrm{NP}$ increased $\mathrm{H}_{2} \mathrm{O}_{2}$ levels; however in cerebellum/medulla oblongata and striatum, $3 \mathrm{NP}$ did not produce significant change in the levels of $\mathrm{H}_{2} \mathrm{O}_{2}$. In the group of animals treated with selenium or CDX alone, the levels of $\mathrm{H}_{2} \mathrm{O}_{2}$ increased in cortex and cerebellum/medulla oblongata when compared with the control group.

The co-administration of selenium $+3 \mathrm{NP}$ produced an increase in the levels of $\mathrm{H}_{2} \mathrm{O}_{2}$ in the cortex and cerebellum/medulla oblongata as opposed to the control group. The same effect was observed in the group with CDX $+3 \mathrm{NP}$ in the cerebellum/medulla oblongata. Although, the increase observed in the CDX + 3NP group in this region was less when compared with the group treated with $\mathrm{CDX}$ alone and the control group, it was not statistically significant. In the striatum, a significant change attributable to any of the treatments was not observed (Figure 1).

In the heart, the treatment with selenium alone and $3 \mathrm{NP}$ alone induced a significant increase in the levels of $\mathrm{H}_{2} \mathrm{O}_{2}$ with respect to the other groups. $\mathrm{H}_{2} \mathrm{O}_{2}$ levels decreased with the combination of $\mathrm{Se}+3 \mathrm{NP}$ when compared with selenium alone. The same occurred with the combination of CDX + 3NP and 3NP.

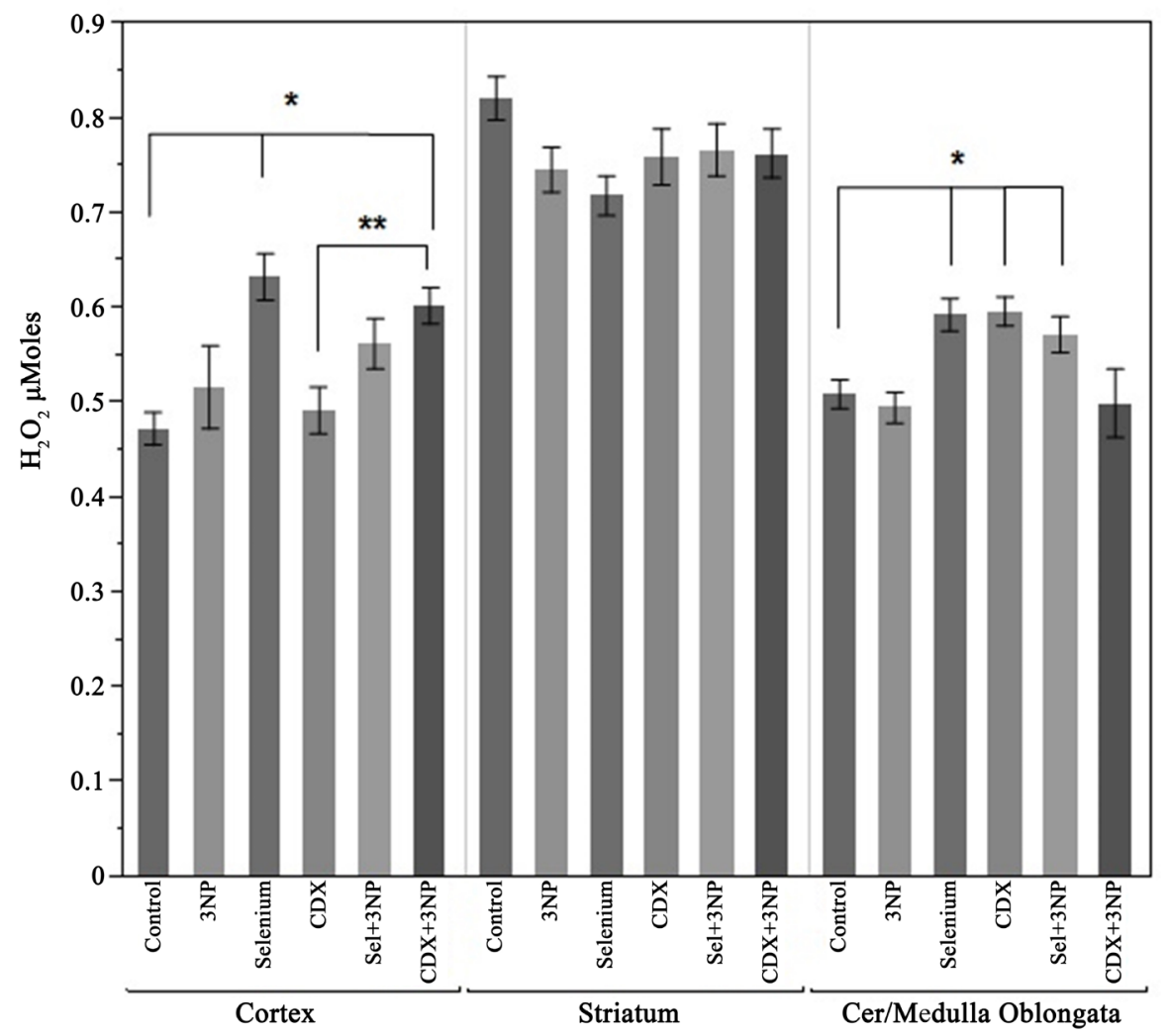

Figure 1. $\mathrm{H}_{2} \mathrm{O}_{2}$ levels on heart and brain regions of animals treated with cardioxane (CDX) and selenium (Se) in the presence of 3-nitropropionic acid (3NP). Wilcoxon/Kruskal Wallis test. ${ }^{\star} \mathrm{p}<0.05,{ }^{* *} \mathrm{p}<0.05$ vs $\mathrm{CDX}$. 


\subsection{ATPase}

The administration of 3NP alone did not produce significant change in the activity of this enzyme in the cortex and striatum. However, in the cerebellum/medulla oblongata, an increase in the activity of the enzyme was observed. Also in this region, the ATPase activity increased in the group treated with selenium alone or $\mathrm{Se}+3 \mathrm{NP}$ in comparison with the control. In the groups treated with CDX alone and $\mathrm{CDX}+3 \mathrm{NP}$, the enzyme activity was not different from the control (Figure 2).

In the heart, the administration of $3 \mathrm{NP}$ did not produce a significant change. In the groups that received Se alone, ATPase activity witnesses an increase in this region, while in the animals treated with CDX alone the activity of the enzyme was lower when compared with those treated with a combination of CDX $+3 \mathrm{NP}$.

\subsection{Dopamine (DA)}

The administration of 3NP either alone or in combination with Se increased the concentration of dopamine in the cortex; however, in other regions, this bioamine did not witness significant change. In the cortex, the group treated with selenium $+3 \mathrm{NP}$ was found to have significant increase when weighed against the control group and the group treated with selenium alone. When the animals

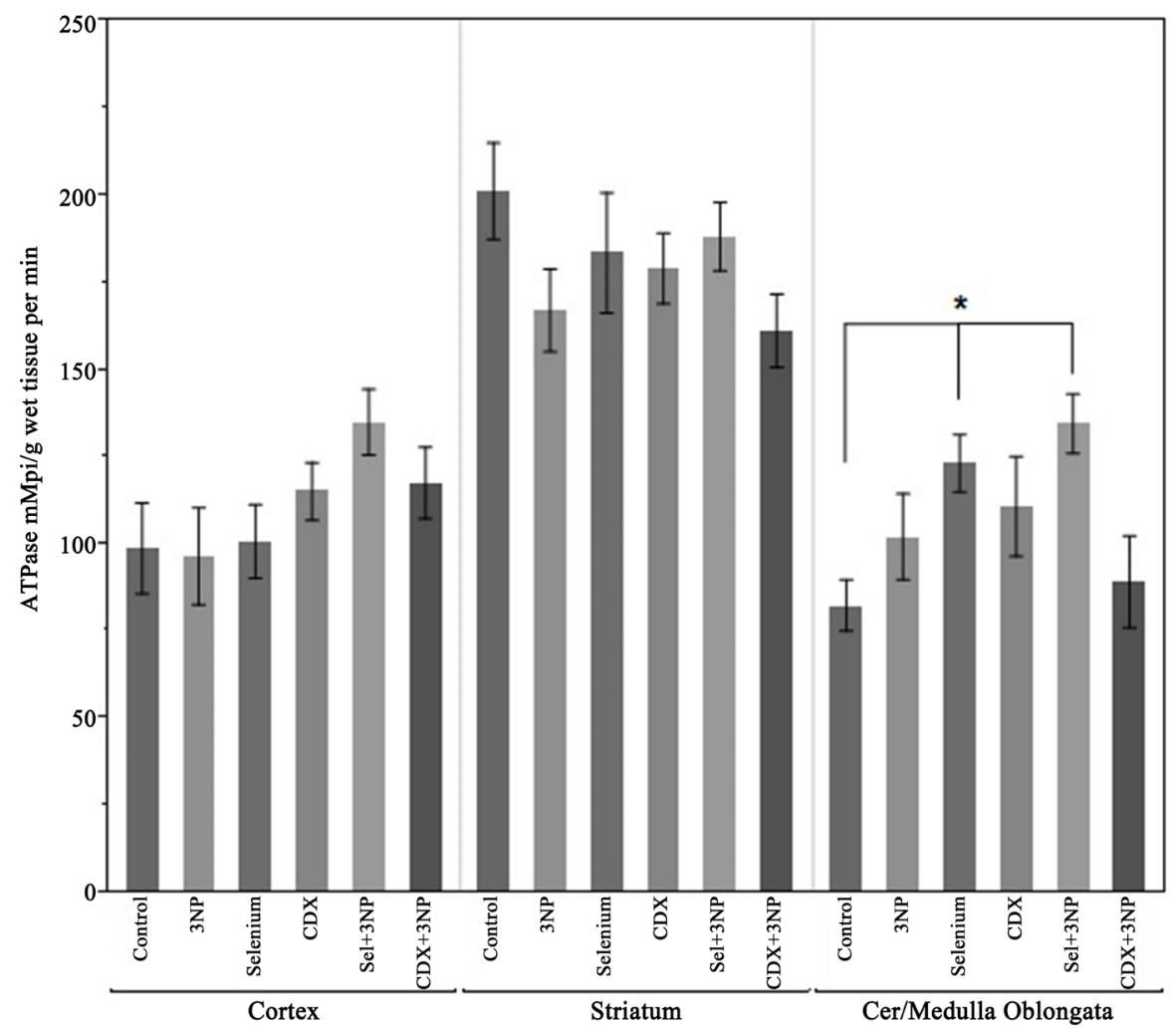

Figure 2. Activity of ATPase dependent of calcium and magnesium on heart and brain regions of animals treated with cardioxane (CDX) and selenium $(\mathrm{Se})$ in the presence of 3-nitropropionic acid (3NP). Wilcoxon/Kruskal Wallis test. ${ }^{\star} \mathrm{p}<0.05$ vs control. 
with the administration of $\mathrm{CDX}+3 \mathrm{NP}$ are compared with the control group, there was no difference in the concentration of dopamine in this region. In the striatum, no effect attributable to the administration of the different drugs was observed in the concentration of this indicator. In cerebellum/medulla oblongata, the administration of selenium, $\mathrm{CDX}$ alone or $\mathrm{CDX}+3 \mathrm{NP}$ produced a significant decrease in the concentration of dopamine with respect to the control. In the group with administration of $\mathrm{Se}+3 \mathrm{NP}$, difference in the concentration of this bioamine was not appreciated when compared with the control group. However, the group treated with selenium alone showed lower concentration of the bioamine than that observed with the administration of Se + 3NP (Figure 3).

\subsection{GSH}

In the three brain regions, a decrease was observed in the levels of GSH in the group treated with $3 \mathrm{NP}$. However, this decrease was not statistically significant in all the regions when compared with the control. In the cortex, the administration of Se + 3NP provoked a significant increase in the levels of GSH, while in

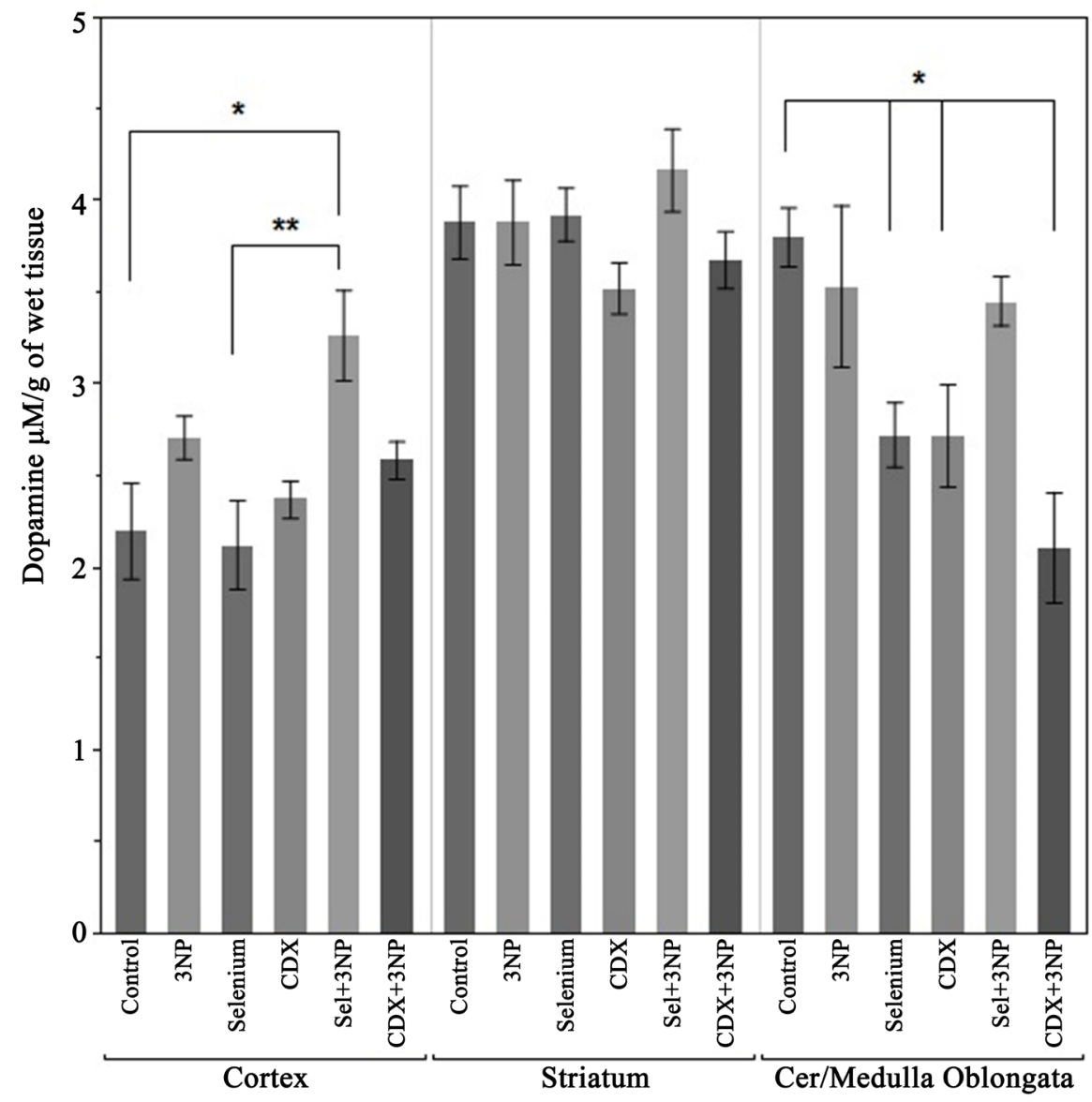

Figure 3. Dopamine levels on brain regions of animals treated with cardioxane (CDX) and selenium (Se) in the presence of 3-nitropropionic acid (3NP). Wilcoxon/KruskallWallis test. ${ }^{\star} \mathrm{p}<0.05$ vs control, ${ }^{\star *} \mathrm{p}<0.05$ vs Selenium. 
the group treated with CDX + 3NP there was no difference when compared with the control. In striatum and medulla oblongata, a significant decrease in GSH was observed in the animals treated with $\mathrm{CDX}+3 \mathrm{NP}$. In striatum of the rest of the groups, no effect on the levels of GSH was observed. In cerebellum/medulla oblongata, the administration of Se + 3NP significantly increased the concentration of GSH (Figure 4).

In the heart of the group that received 3NP, there was a decrease in the concentration of GSH which reflects oxidative damage in the target organ. The administration of CDX increased the levels of GSH, nevertheless the most significant increase was observed in the animals treated with Se.

\subsection{Calcium}

In the concentration of calcium, no effect was observed in any of the brain regions studied as a result of the administration of the experimental drugs (Figure 5).

\subsection{TBARS}

The administration of $3 \mathrm{NP}$ produced a significant increase in lipid peroxidation in the three brain regions studied. The biggest increase in the level of TBARS was observed in the striatum of the animals treated with selenium in comparison

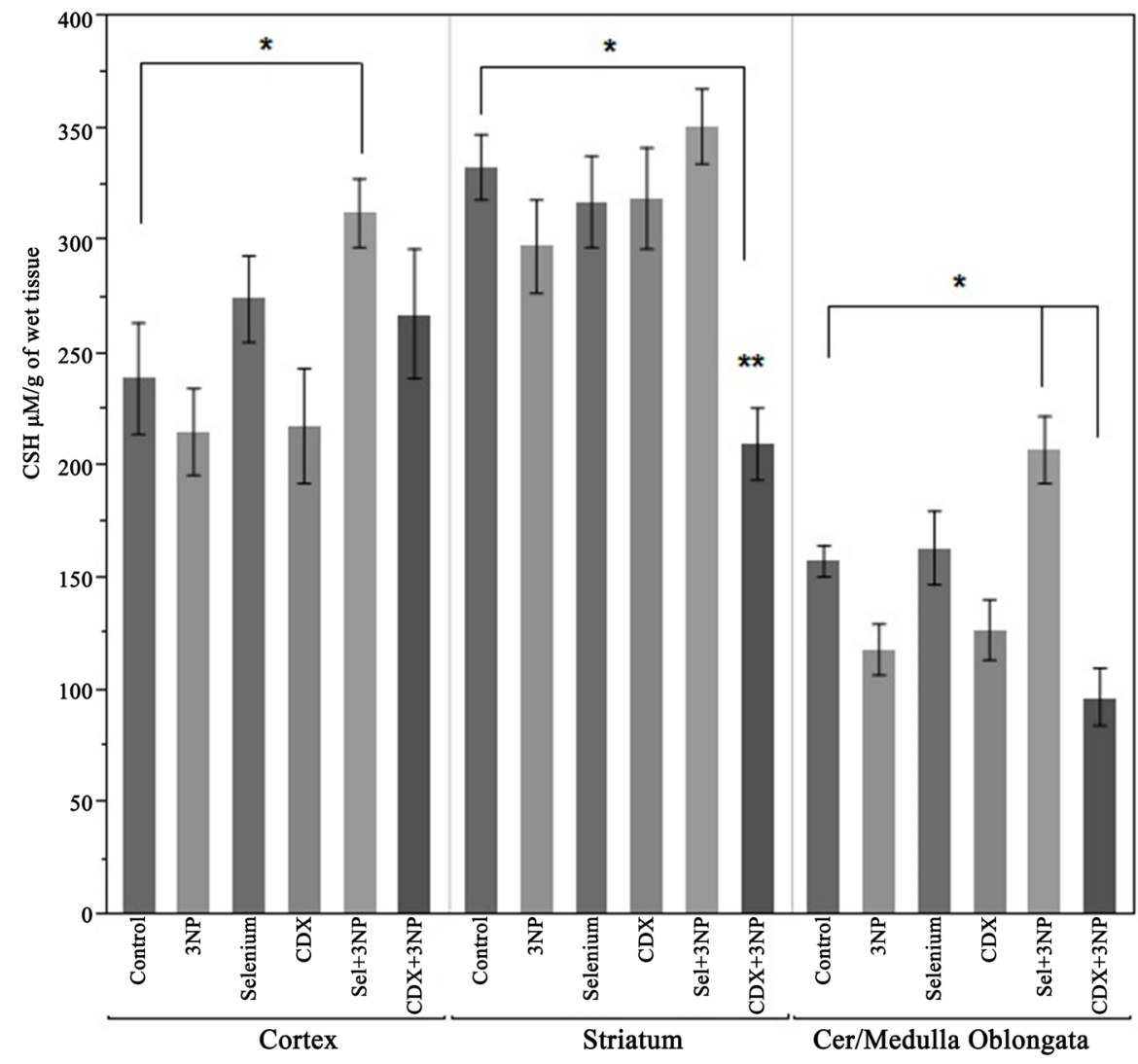

Figure 4. GSH levels on heart and brain regions of animals treated with cardioxane $(\mathrm{CDX})$ and selenium $(\mathrm{Se})$ in the presence of 3-nitropropionic acid (3NP). ANOVA test. ${ }^{*} \mathrm{p}<0.05$ vs control, ${ }^{* *} \mathrm{p}<0.05$ vs $\mathrm{CDX}$. 


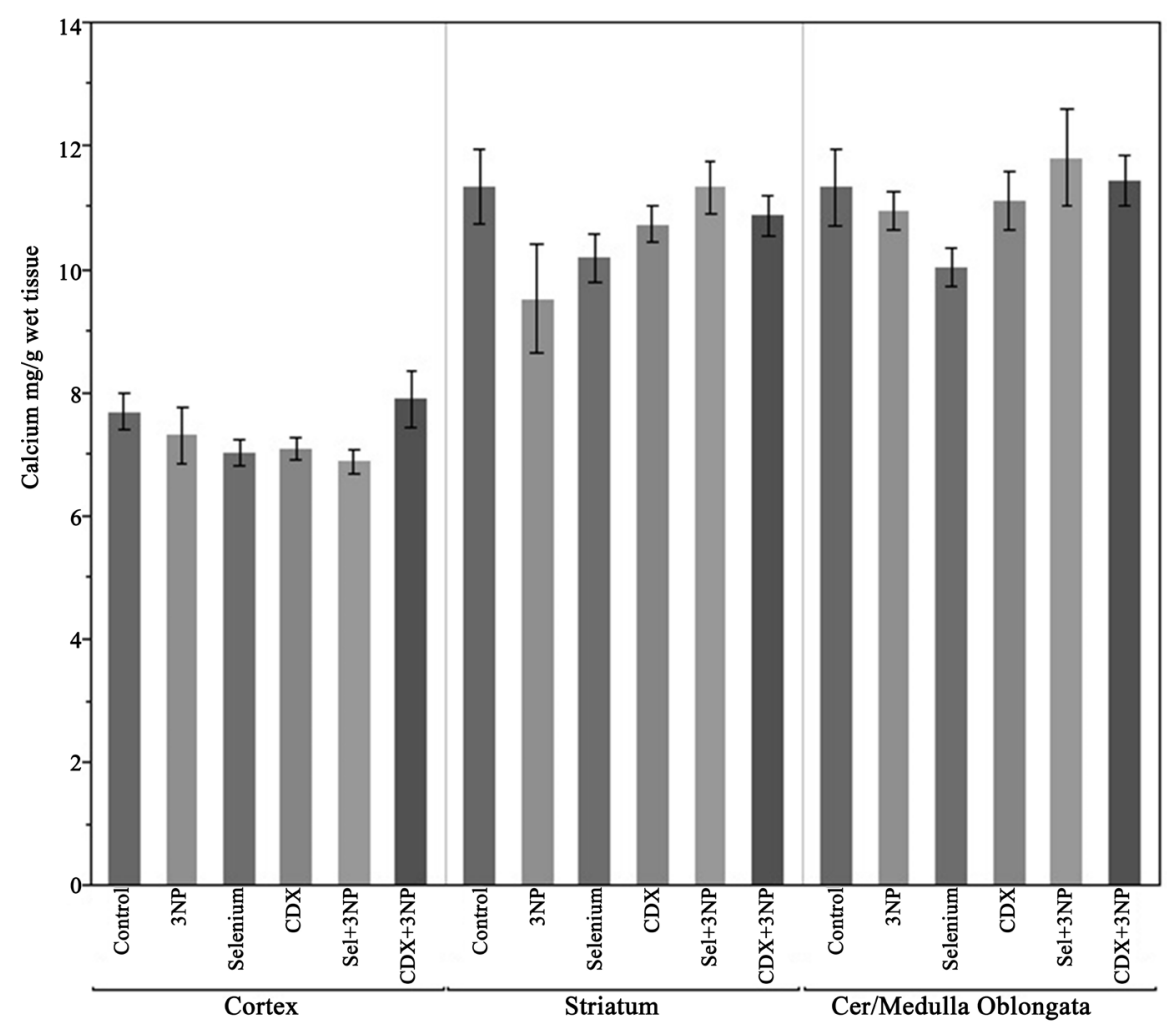

Figure 5. Calcium levels on heart and brain regions of animals treated with cardioxane (CDX) and selenium (Se) in the presence of 3-nitropropionic acid (3NP).

with the control. On the other hand, the addition of selenium to $3 \mathrm{NP}$ was able to reduce TBARS to the levels found in the control. In contrast, the joint administration of CDX and 3NP provoked a significant increase in lipid peroxidation as compared to the control. On comparing the groups treated with $\mathrm{Se}+3 \mathrm{NP}$ against the animal group that received selenium alone, a significant increase was observed in the three regions. In cortex, the administration of CDX + 3NP upgraded the levels of lipid peroxidation more than what was found in the group treated with 3NP alone (Figure 6).

In the heart, TBARS increased with the administration of $3 \mathrm{NP}$. The group treated with CDX maintained lower levels of TBARS when compared with the group treated with Se; however, both treatments increased lipid peroxidation markers.

\section{Discussion}

There is evidence that the metabolism of dopamine by monoamine oxidase enzyme is an important source of free radicals and oxidative stress, which may contribute to tissue damage. This amine is concentrated in the dopaminergic systems, mainly in the striatal region, as reflected in Huntington disease models by the mitochondrial toxins [20], developed by a neurodegenerative process that manifests neuronal dysfunction and which progresses to the death of these cerebral regions, principally the cerebral cortex and striatum [21]. 


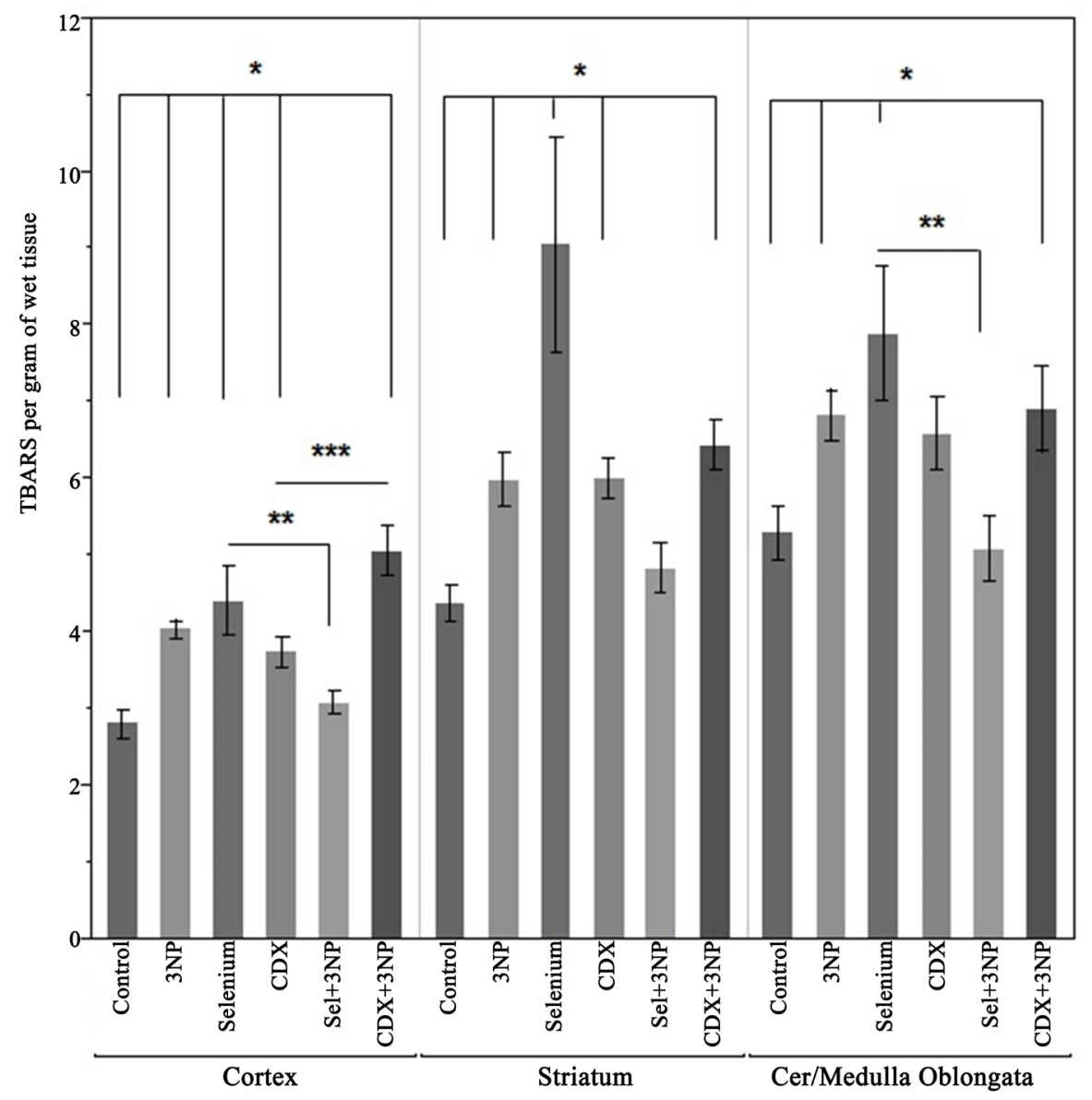

Figure 6. Tbars levels on heart and brain regions of animals treated with cardioxane $(\mathrm{CDX})$ and selenium (Se) in the presence of 3-nitropropionic acid (3NP). Wilcoxon/Kruskal Wallis test. ${ }^{\star} \mathrm{p}<0.05$ vs control, ${ }^{\star *} \mathrm{p}<0.05$ vs Selenium, ${ }^{\star * *} \mathrm{p}<0.05$ vs CDX.

Controversially, the result of the present study found that dopamine levels increased in the cerebral cortex of the animals that received 3NP without significant changes in the rest of the regions studied. In contrast, in the animals treated with CDX, this drug decreased dopamine levels in cerebellum/medulla oblongata region. In the group treated with Se, the levels of dopamine decreased. This effect is in accordance with the reports of Qureshi et al. [22], who found a clear evidence of the relation between the increase in selenium levels and decrease in the concentration of dopamine in the brain. Romero-Ramos et al. [23] suggest that the decrease in the capacity of antioxidant due to Selenium deficiency, promotes an increase in the synthesis and turnover of DA and that these effects are clearly associated with the induction of tyrosine hydroxylase. In the same way, Castaño et al. [24], suggested that the increase in dopamine turnover probably alters the activity of monoamine oxidase enzyme.

Glutathione is considered an antioxidant by excellence in spite of the fact that oxidized glutathione is reduced by glutathione reductase, which through the enzyme glutathione peroxidase reduces hydrogen peroxide $\left(\mathrm{H}_{2} \mathrm{O}_{2}\right)$ and lipoperoxides (L-OOH). In the present study, lipoperoxidation and the concentration of 
$\mathrm{H}_{2} \mathrm{O}_{2}$ increased in the regions of cardiac tissue, cortex, striatum and cerebellum/medulla oblongata in the animals treated with selenium, since the reactive oxygen species are the main event in the toxicity of 3NP [25]. These results do not coincide with the reports of Kumar et al. [26], who suggested that 3NP depleted GSH in the cortex or by the enzymatic saturation. This lack of coincidence may probably be owed to the fact that the present study was performed in young animal models.

Calcium-magnesium-dependent ATPase activity decreased in the heart and cortex regions of the animals that received selenium alone or combined, probably as a consequence of the changes in the enzyme affinity [27]. This effect may probably be because cellular calcium signaling is subjected to thiol-redox regulation by the selenoproteins [28] [29]. These results could be related with the reports of Naziroglu et al. [30], who suggested that selenium increases the activity of $\mathrm{Ca}^{2+}$-ATPase thus, producing protective effect on the substances that increase brain lesions, by the inhibition of free radical production and regulation of calcium-dependent processes, as well as supporting the redox antioxidant system. Some studies suggested that CDX might play an important role in the regulation of redox state within the cells of the brain and the heart [31].

\section{Conclusions}

Selenium increased the levels of GSH in the animals. Although it did not alter dopamine metabolism, it decreased lipoperoxidation and $\mathrm{H}_{2} \mathrm{O}_{2}$ concentration, and increased $\mathrm{H}_{2} \mathrm{O}_{2}$ levels in the presence of an aggressive agent, a result which can be translated as neuroprotector and which acts, in the same way, against the presence of oxidative damage in the heart, thus restoring stability of this organ in this kind of damage.

Cardioxane, when administered in the presence of oxidative damage, stabilizes the brain damage and maintains the deterioration of dopamine metabolism in this organ in view of the ability of 3-nitopropionic acid to generate free radicals. The same happens with GSH levels. However, in the heart, its protective action is demonstrated.

\section{Acknowledgements}

We thank Dr. Cyril Ndidi Nwoye Nnamezie, an expert translator whose native language is English, for his help in preparing this manuscript.

\section{Funding}

We thank to Instituto Nacional de Pediatría for the support to publish this article.

\section{Authors' Contributions}

$\mathrm{DCG}^{\mathrm{a}, \mathrm{b}, \mathrm{c}, \mathrm{d}, \mathrm{e}}, \mathrm{NOB}^{\mathrm{b}, \mathrm{d}, \mathrm{e}}, \mathrm{GBM}^{\mathrm{b}, \mathrm{d}, \mathrm{e}}, \mathrm{HJO}^{\mathrm{c}, \mathrm{d}, \mathrm{e}}, \mathrm{LSR}^{\mathrm{c}, \mathrm{d}, \mathrm{e}}, \mathrm{AVP}^{\mathrm{b}, \mathrm{d}, \mathrm{e}}, \mathrm{NLR}^{\mathrm{b}, \mathrm{d}, \mathrm{e}}, \mathrm{DSA}^{\mathrm{c}, \mathrm{d}, \mathrm{e}}$

(a) Contributed to the conception and design of the work; (b) Contributed to the collection, analysis, or interpretation of data; (c) Critically revised the ma- 
nuscript for important intellectual content; (d) Drafted manuscript; (e) Gave final approval.

\section{Conflicts of Interest}

The authors declare no conflicts of interest regarding the publication of this paper.

\section{References}

[1] Rami, A., Ferger, D. and Krieglstein, J. (1997) Blockade of Calpain Proteolytic Activity Rescues Neurons from Glutamate Excitotoxicity. Neuroscience Research, 27, 93-97. https://doi.org/10.1016/S0168-0102(96)01123-6

[2] Aliev, G., Obrenovich, M.E., Tabrez, S., et al. (2013) Link between Cancer and Alzheimer Disease via Oxidative Stress Induced by Nitric Oxide-Dependent Mitochondrial DNA Overproliferation and Deletion. Oxidative Medicine and Cellular Longevity, 2013, Article ID: 962984. https://doi.org/10.1155/2013/962984

[3] Russo, E., Donato di Paola, E., Gareri, P., et al. (2013) Pharmacodynamic Potentiation of Antiepileptic Drugs' Effects by Some HMG-CoA Reductase Inhibitors against Audiogenic Seizures in DBA/2 Mice. Pharmacological Research, 70, 1-12. https://doi.org/10.1016/j.phrs.2012.12.002

[4] Tetef, M.L., Synold, T.W., Chow, W., et al. (2001) Phase I Trial of 96-Hour Continuous Infusion of Cardioxane in Patients with Advanced Malignancies. Clinical Cancer Research, 7, 1569-1576.

[5] Driver, A.S., Kodavanti, P.R. and Mundy, W.R. (2000) Age-Related Changes in Reactive Oxygen Species Production in Rat Brain Homogenates. Neurotoxicology and Teratology, 22, 175-181. https://doi.org/10.1016/S0892-0362(99)00069-0

[6] Vogt, M.C. and Brüning, J.C. (2012) CNS Insulin Signaling in the Control of Energy Homeostasis and Glucose Metabolism from Embryo to Old Age. Trends in Endocrinology \& Metabolism, 24, 76-84. https://doi.org/10.1016/j.tem.2012.11.004

[7] Bellinger, F.P., Raman, A.V., Rueli, R.H., et al. (2012) Changes in Selenoprotein P in Substantia Nigra and Putamen in Parkinson's Disease. Journal of Parkinson's Disease, 2, 115-126.

[8] Swapna, I., Sathya, K.V., Murthy, C.R. and Senthilkumaran, B. (2005) Membrane Alterations and Fluidity Changes in Cerebral Cortex during Ammonia Intoxication. NeuroToxicology, 335, 700-704.

[9] Stefanello, F.M., Chiarani, F., Kurek, A.G., et al. (2005) Methionine alters $\mathrm{Na}^{+}, \mathrm{K}^{+}$ ATPase Activity, Lipid Peroxidation and Nonenzymatic Antioxidant Defenses in Rat Hippocampus. International Journal of Developmental Neuroscience, 23, 651 656. https://doi.org/10.1016/j.ijdevneu.2005.06.003

[10] Calderon, G.D., Juarez, O.H., Hernandez, G.E., et al. (2013) Effect of an Antiviral and Vitamins A,C,D on Dopamine and Some Oxidative Stress Markers in Rat Brain Exposed to Ozone. Archives of Biological Sciences, 65, 1371-1379. https://doi.org/10.2298/ABS1304371G

[11] Junior, E.L., Leite, H.P. and Konstantyner, T. (2019) Selenium and Selenoproteins: From Endothelial Cytoprotection to Clinical Outcomes. Translational Research, 208, 85-104.

[12] Reynolds, D.S., Carter, R.J. and Morton, A.J. (1998) Dopamine Modulates the Susceptibility of Striatal Neurons to 3-Nitropropionic Acid in the Rat Model of Hun- 
tington's Disease. The Journal of Neuroscience, 18, 10116-10127. https://doi.org/10.1523/JNEUROSCI.18-23-10116.1998

[13] Calderón, G.D., Osnaya, B.N., García, A.R., et al. (2008) Levels of Glutathione and Some Biogenic Amines in the Human Brain Putamen after Traumatic Death. Proceedings of the Western Pharmacology Society, 51, 25-32.

[14] Hissin, P.J. and Hilf, R. (1974) A Flurometric Method for Determination of Oxidized and Reduced Glutathione in Tissue. Analytical Biochemistry, 4, 214-226. https://doi.org/10.1016/0003-2697(76)90326-2

[15] Calderón-Guzmán, D., Espitia-Vázquez, I., López-Domínguez, A., et al. (2005) Effect of Toluene and Nutritional Status on Serotonin, Lipid Peroxidation Levels and $\mathrm{Na}^{+} / \mathrm{K}^{+}$-ATPase in Adult Rat Brain. Neurochemical Research, 30, 619-624. https://doi.org/10.1007/s11064-005-2749-2

[16] Fiske, C.H. and Subbarow, Y. (1925) The Colorimetric Determination of Phosphorus. The Journal of Biological Chemistry, 66, 375-400.

[17] Asru, K.S. (1972) Colorimetric Assay of Catalase. Analytical Biochemistry, 47, 389394. https://doi.org/10.1016/0003-2697(72)90132-7

[18] Gutteridge, J.M. and Halliwell, B. (1990) The Measurement and Mechanism of Lipid Peroxidation in Biological Systems. Trends in Biochemical Sciences, 15, 129-135. https://doi.org/10.1016/0968-0004(90)90206-Q

[19] Castilla-Serna, L. (2011) Practical Statistical Guide for Health Science. Editorial Trillas, México.

[20] Smith, R.R., Dimayuga, E.R., Keller, J.N. and Maragos, W.F. (2005) Enhanced Toxicity to the Catecholamine Tyramine in Polyglutamine Transfected SH-SY5Y Cells. Neurochemical Research, 30, 527-531. https://doi.org/10.1007/s11064-005-2687-z

[21] Browne, S.E. and Beal, M.F. (2006) Oxidative Damage in Huntington's Disease Pathogenesis. Antioxidants \& Redox Signaling, 8, 2061-2073.

https://doi.org/10.1089/ars.2006.8.2061

[22] Qureshi, G.A., Qureshi, A.A., Memon, S.A. and Parvez, S.H. (2006) Impact of Selenium, Iron, Copper and Zinc in on/off Parkinson's Patients on L-Dopa Therapy. Journal of Neural Transmission. Supplementa, 71, 229-236. https://doi.org/10.1007/978-3-211-33328-0_24

[23] Romero-Ramos, M., Venero, J.L., Cano, J. and Machado, A. (2000) Low Selenium Diet Induces Tyrosine Hydroxylase Enzyme in Nigrostriatal System of the Rat. Molecular Brain Research, 84, 7-16. https://doi.org/10.1016/S0169-328X(00)00171-6

[24] Castaño, A., Ayala, A., Rodriguez-Gomez, J.A., et al. (1995) Increase in Dopamine Turnover and Tyrosine Hydroxylase Enzyme in Hippocampus of Rats Fed on Low Selenium Diet. Journal of Neuroscience Research, 42, 684-691. https://doi.org/10.1002/jnr.490420511

[25] Mandavilli, B.S., Boldogh, I. and Van Houten, B. (2005) 3-Nitropropionic Acid-Induced Hydrogen Peroxide, Mitochondrial DNA Damage, and Cell Death Are Attenuated by Bcl-2 Overexpression in PC12 Cells. Molecular Brain Research, 133, 215-223. https://doi.org/10.1016/j.molbrainres.2004.10.033

[26] Kumar, P., Kalonia, H. and Kumar, A. (2010) Protective Effect of Sesamol against 3-Nitropropionic Acid-Induced Cognitive Dysfunction and Altered Glutathione Redox Balance in Rats. Basic \& Clinical Pharmacology \& Toxicology, 107, 577-582. https://doi.org/10.1111/j.1742-7843.2010.00537.x

[27] Hoskins, B., Ho, I.K. and Meydrech, E.F. (1985) Effects of Aging and Morphine 
Administration on Calmodulin and Calmodulin-Regulated Enzymes in Striata of Mice. Journal of Neurochemistry, 44, 1069-1073.

https://doi.org/10.1111/j.1471-4159.1985.tb08726.x

[28] Zheng, Y., Zhong, L. and Shen, X. (2005) Effect of Selenium-Supplement on the Calcium Signaling in Human Endothelial Cells. Journal of Cellular Physiology, 205, 97-106. https://doi.org/10.1002/jcp.20378

[29] Barrett, C.W., Short, S.P. and Williams, C.S. (2016) Selenoproteins and Oxidative Stress-Induced Inflammatory Tumorigenesis in the Gut. Cellular and Molecular Life Sciences, 74, 607-616.

[30] Naziroğlu, M., Kutluhan, S. and Yilmaz, M. (2008) Selenium and Topiramate Modulates Brain Microsomal Oxidative Stress Values, $\mathrm{Ca}^{2+}$-ATPase Activity, and EEG Records in Pentylentetrazol-Induced Seizures in Rats. Journal of Membrane Biolo$g y, 225,39-49$. https://doi.org/10.1007/s00232-008-9132-6

[31] Hogg, N., Singh, R.J. and Kalyanaraman, B. (1996) The Role of Glutathione in the Transport and Catabolism of Nitric Oxide. FEBS Letters, 382, 223-228.

https://doi.org/10.1016/0014-5793(96)00086-5 